\title{
Right Heart Functional Changes in the Acute, Hypercapnic Exacerbations of COPD
}

\author{
Claudio Terzano, ${ }^{1}$ Sofia Romani, ${ }^{1}$ Carlo Gaudio, ${ }^{2}$ Francesco Pelliccia, ${ }^{2}$ \\ Mattia Serao, ${ }^{1}$ and Antonio Vitarelli ${ }^{3}$ \\ ${ }^{1}$ Respiratory Diseases Unit, ALS Respiratory and Critical Care Unit, School of Specialization in Respiratory Diseases, \\ Sapienza University, Viale del Policlinico No. 155, 00161 Rome, Italy \\ ${ }^{2}$ Department of Heart and Great Vessels Attilio Reale, Sapienza University, Viale del Policlinico No. 155, 00161 Rome, Italy \\ ${ }^{3}$ Sapienza University, Viale del Policlinico No. 155, 00161 Rome, Italy
}

Correspondence should be addressed to Claudio Terzano; claudio.terzano@uniromal.it

Received 17 April 2014; Accepted 25 April 2014; Published 23 June 2014

Academic Editor: Salvatore Rosanio

Copyright (C) 2014 Claudio Terzano et al. This is an open access article distributed under the Creative Commons Attribution License, which permits unrestricted use, distribution, and reproduction in any medium, provided the original work is properly cited.

Objective. To investigate the correlation between respiratory failure and the pulmonary circulation. We focused on anatomical and functional changes of the right heart. Design. Clinical investigation. Methods. We evaluated 75 patients hospitalized in our respiratory ward for COPD exacerbation. All patients underwent transthoracic echocardiography and measurements of right heart chambers. Moreover all patients underwent blood tests, measurement of blood pressure, evaluation of body mass index (BMI), ECGs, pulmonary function tests, and the Saint George's Respiratory Questionnaire (SGRQ). Results. Among 75 patients consecutively hospitalized, 56 patients with a COPD exacerbation were included in our study. We have emphasized the higher value of PAPs and the increased size of right atrial area in severe COPD patients. Significant correlation was observed between low values of $\mathrm{PaO}_{2}$ and larger area of the right atrium. The measurement of TAPSE showed a right ventricular dysfunction in all patients but especially in severe COPD patients. We have obtained a significant correlation between TAPSE and arterial blood gas. Conclusions. In patients with chronic respiratory failure, blood gas parameters should be considered as negative prognostic factors of right heart failure. Respiratory failure shows a relationship with pulmonary hypertension and with the anatomy and function of the right heart sections.

\section{Introduction}

The chronic obstructive pulmonary disease (COPD) is a chronic disease of the respiratory system characterized by a persistent and irreversible airway obstruction associated with chronic inflammation of the airways and the systemic circulation [1].

The disease is worsening and it is characterized by a tendency to exacerbate with several comorbidities [2]. The WHO estimates that it will become the third leading cause of death in 2020 [3].

Diagnosis of COPD should be considered in the presence of cough and dyspnea, with or without sputum associated with a Tiffeneau index $\left(\mathrm{FEV}_{1} / \mathrm{VC}\right) \leq 70$ after bronchodilator at a spirometry [1].
The analysis of $\mathrm{FEV}_{1}$, together with the use of questionnaires as modified Medical Research Council Dyspnea (mMRC) Scale, body mass index, airflow obstruction, dyspnea, and Exercise Capacity Index (BODE) or St. George's Respiratory Questionnaire (SGRQ) and evaluation of the rate of exacerbation per year will allow us to quantify the seriousness of the disease $[4,5]$.

COPD often coexists with other comorbidities such as lung cancer, respiratory infections, diabetes mellitus, osteoporosis, increased incidence of atrial fibrillation, arterial hypertension, heart failure, and ischemic heart disease $[2,6,7]$.

The study and evaluation of comorbidity leads the clinician to assess their interdependence and then to look for new diagnostic paths in order to identify them early [7]. 
The prevalence of COPD among individuals with heart failure varies from $20 \%$ to $32 \%$ of cases and the $10 \%$ of patients hospitalized for heart failure also suffer from COPD. On the opposite side heart failure is prevalent in over $20 \%$ of patients with COPD [8]. The relative risk (RR) of developing heart failure in COPD patients is 4.5 times higher than that of control individuals without the disease, after adjustment for cardiovascular risk factors [9-13].

Pulmonary arterial hypertension (PAH) is a chronic, progressive disease characterized by an increase in pulmonary arterial pressure above $25 \mathrm{mmHg}$ leading to right heart failure [14]. The pressure increase in the right ventricular chamber is caused by an increase in afterload and generates a progressive remodeling of the right heart. Nowadays it is known that the actual classification of pulmonary hypertension identifies COPD as a cause of the small circle hypertension [14-16].

The causes are the hypoxic vasoconstriction of the pulmonary vascular bed, the inflammatory situation of COPD which in the lungs would lead to such a fibrotic damage to increase vascular resistance, the toxic effects of cigarette smoking, and, finally, an imbalance between the concentrations of endothelin 1 (ET-1) and nitric oxide (NO) which promotes vasoconstriction [17].

The correlation between the progressive remodeling of the pulmonary vascular bed and the increase of the pressures in the right sections of the heart has been studied by many authors in recent years [18-20]. The incidence of pulmonary hypertension in COPD is around 20\% but more than $50 \%$ in severe chronic bronchitis [21]. The increased interest in the right ventricle has led to several studies about its particular morphology and function which is quite different from the left ventricle [22-25]. The right ventricular chamber is not a passive conduit but an essential part of a circuit characterized by low impedance and high capacitance [26].

The right ventricle is highly susceptible to changes in pressure created by the remodeling of the lung parenchyma in COPD. Tricuspid annular plane systolic excursion (TAPSE) in an apical four-chamber view is a useful surrogate for RV ejection fraction, which indicates the degree of right ventricular function. The level of excursion of the TAPSE, evaluated in $M$-Mode, corresponds with RV ejection fraction (5 mm 20\% RVEF, $10 \mathrm{~mm}$ 30\% RVEF, $15 \mathrm{~mm} \sim 40 \%$ RVEF, and $20 \mathrm{~mm} 50 \%$ RVEF) $[27,28]$.

The survival of the patient does not seem so much likened to the values of pulmonary artery pressure but to the adaptability of the right sections (loading rate, right atrial pressure, and TAPSE) [28-31]. Pulmonary hypertension and right atrium size in COPD is an important element that we must take into account in the diagnostic program of the patient with COPD, although the clinical manifestations of pulmonary hypertension and right heart failure may be hidden behind the COPD symptoms. Echocardiography with Doppler estimation of pulmonary artery pressure and the size of the right chambers are therefore essential to determine the patient's prognosis.

The aim of our study is to investigate the correlation between respiratory failure and alterations in the pulmonary circulation. We specially focused on anatomical and functional changes of the right heart.

\section{Methods}

From November 2013 to February 2014 we analyzed 75 patients consecutively hospitalized in our respiratory ward (Respiratory Diseases Unit, Policlinico Umberto I, Rome, Italy) for COPD exacerbation.

COPD exacerbations were defined according to the Global Initiative for Chronic Obstructive Lung Disease (GOLD) guidelines [1]. According to GOLD criteria, the subjects with airflow limitation and forced expiratory volume in 1 second $\left(\mathrm{FEV}_{1}\right) \%$ predicted $\geq 80$ were identified as having mild airflow limitation, $50 \leq \mathrm{FEV}_{1} \%$ predicted $<80$ were described as moderate, and $\mathrm{FEV}_{1} \%$ predicted $<50$ were described as having severe airway obstruction. $\mathrm{FEV}_{1}$ was measured at baseline using a spirometer (Cosmed, Quark PFT, Pavona, Rome, Italy). We included in our study patients with moderate and severe airway obstruction. Hypoxemia was defined by a $\mathrm{PaO}_{2}<60 \mathrm{mmHg}$ and hypercapnia was defined by a $\mathrm{PaCO}_{2}>45 \mathrm{mmHg}$ on arterial blood gas analysis $(\mathrm{ABG})$. Baseline demographic characteristics and clinical parameters, routine blood chemistry, and ABG were assessed at admission. All patients underwent blood tests, measurement of systolic and diastolic blood pressure, evaluation of body mass index (BMI), ECGs, pulmonary function tests, and disease-specific instrument designed to measure impact on overall health, daily life, and perceived well-being in patients with obstructive airways disease (the Saint George's Respiratory Questionnaire, SGRQ).

All patients underwent transthoracic echocardiography with a commercially available cardiovascular ultrasound system (Vivid E9, GE, Horten, Norway) and measurements of right heart chambers were made according to established criteria [32, 33]. Right ventricular systolic pressure (RVSP) and pulmonary artery systolic pressure (PAPs) were determined by continuous wave Doppler echocardiography [14]. Right atrial pressure was estimated according to caval dimensions [34]. RVSP can be estimated from right atrial pressure using the equation RVSP $=4(\mathrm{VTR})^{2}+\mathrm{RAP}$, where VTR is peak TR velocity $(\mathrm{m} / \mathrm{s})$ and $\mathrm{RAP}$ is mean right atrial pressure $(\mathrm{mmHg})$. The mean RAP is estimated using inferior vena cava (IVC) size and reactivity as per American Society of Echocardiography (ASE) recommendations [34]. Estimation of pulmonary vascular resistance (PVR) was determined as previously described [35]. The measurement of TAPSE estimates right ventricle (RV) systolic function by measuring the level of systolic excursion of the lateral tricuspid valve annulus toward the apex in the four-chamber view [28]. A TAPSE $>21 \mathrm{~mm} / \mathrm{s}$ was consistently observed in the normal population [36]. The echocardiographic assessment was performed during diagnostic tests and patients were not subjected to specific treatment for pulmonary hypertension but only to specific therapy for COPD $\left(\beta_{2}\right.$-agonists, corticosteroids, chemotherapy, oxygen therapy, and, if necessary, noninvasive mechanical ventilation).

Physical examination was performed and comorbidities were identified on the basis of concomitant therapy and investigations carried out at hospital admission. 
TABLE 1: Patients demographics and clinical characteristics (data expressed as mean \pm standard deviation).

\begin{tabular}{|c|c|c|c|c|}
\hline Variables & Total $(n=56)$ & Moderate COPD $(n=21)$ & Severe COPD $(n=35)$ & $P$ value \\
\hline Gender: male $(n, \%)$ & $38(67.8)$ & $16(76)$ & $22(62.8)$ & $0.06^{\mathrm{b}}$ \\
\hline Age (years) & $79.1 \pm 5.1$ & $79.2 \pm 5.4$ & $78.2 \pm 4.9$ & $0.611^{\mathrm{a}}$ \\
\hline $\operatorname{BMI}\left(\mathrm{Kg} / \mathrm{m}^{2}\right)$ & $26.2 \pm 2.6$ & $26.1 \pm 3.3$ & $26.5 \pm 2.1$ & $0.856^{\mathrm{a}}$ \\
\hline SBP (mmHg) & $127.6 \pm 16.9$ & $125.8 \pm 17.7$ & $135.2 \pm 16.2$ & $0.156^{\mathrm{a}}$ \\
\hline DBP (mmHg) & $72.4 \pm 8.2$ & $70.6 \pm 9.8$ & $80.2 \pm 6.7$ & $0.097^{\mathrm{a}}$ \\
\hline Fasting blood glucose & $119.3 \pm 8.7$ & $119.8 \pm 7.2$ & $117.3 \pm 9.3$ & $0.773^{\mathrm{a}}$ \\
\hline Diabetes mellitus $(n, \%)$ & $41(73.2)$ & $18(85.7)$ & $23(65.7)$ & $0.08^{\mathrm{b}}$ \\
\hline Renal failure $(n, \%)$ & $11(19.6)$ & $6(28.5)$ & $5(14.28)$ & $0.23^{\mathrm{b}}$ \\
\hline Current smokers $(n, \%)$ & $49(87.5)$ & $15(71.4)$ & $34(97)$ & $0.654^{\mathrm{a}}$ \\
\hline
\end{tabular}

${ }^{\mathrm{a} S}$ Student's $t$-test for unpaired data; ${ }^{\mathrm{b}}$ chi-squared test;

BMI: body mass index; SBP: systolic blood pressure; DBP: diastolic blood pressure; COPD: chronic obstructive pulmonary disease.

Among patients consecutively hospitalized in our respiratory ward, were excluded patients with severe cardiomyopathies, chronic ischemic heart disease, resistant hypertension, atrial septal defect, valvular heart disease, thyroid dysfunction, and severe arrhythmia, patients with severe hydroelectrolyte disorders, cancer patients, and patients with severe systemic complications or previous cardiovascular disease.

In addition, we excluded patients with other causes of primary pulmonary hypertension such as interstitial lung disease, sleep-disordered breathing, and alveolar hypoventilation disorders, other pulmonary diseases with mixed restrictive and obstructive pattern, chronic exposure to high altitude, vasculitis, pneumoconiosis, congenital heart disease, and occlusion of pulmonary veins syndrome.

Written informed consent was obtained from all the participants.

2.1. Statistical Analysis. Continuous variables are presented as mean \pm standard deviation (SD), and differences were evaluated by paired Student's $t$-test or Wilcoxon test, depending on the shape of the distribution curve. Categorical variables are expressed by count and percentage and compared by $\chi^{2}$ or Fisher's exact test when appropriated.

The Spearman coefficient was used for measuring linear correlation between variables.

The probability values are 2 -sided; a probability value $<0.05$ was considered to indicate statistical significance.

Statistical analyses were performed by using the software SigmaStat (San Jose, California). Power analysis was performed using STATA v.11 (College Station, TX).

\section{Results}

Among 75 patients consecutively hospitalized in our respiratory ward for COPD exacerbation, 19 (25.3\%) were excluded because of several complications. Three of these died for cardiac complications, four patients were excluded for major metabolic disorders, and two patients died for neurological disease not related to hypercapnia. The remaining ten patients were excluded for iatrogenic complications (two patients), myocardial ischemia (one patient), severe renal failure (three patients), and diagnosis of cancer (three patients). Thus 56 patients with a COPD exacerbation were included in our study.

Participants baseline characteristics are summarized in Table 1 .

The subjects studied were more males than females. BMI, blood pressure, blood glucose, and the presence of diabetes mellitus, tobacco consumption, and renal failure did not significantly differ between subjects with moderate COPD and severe COPD.

As showed in Table 2, higher levels of $\mathrm{PaO}_{2}$ are prevalent in moderate COPD patients $(64.2 \mathrm{mmHg} \pm 4.6$ versus $56.5 \mathrm{mmHg} \pm 2.96 ; P<0.05)$. Similarly higher levels of $\mathrm{PaCO}_{2}$ are prevalent in severe COPD patients $(72.6 \mathrm{mmHg} \pm$ 5.3 versus $55.2 \mathrm{mmHg} \pm 3.5 ; P<0.05$ ). In addition we have shown a negative trend regarding the EF\% (ejection fraction) in patients with severe COPD but not statistically significant.

The assessment of the right heart dimension was available in all 56 subjects. We have emphasized the higher value of PAPs and the increased of right atrial area in severe COPD patients $(45.3 \mathrm{mmHg} \pm 3.5$ versus $30.2 \mathrm{mmHg} \pm 2.3 ; P<0.05$ and $33.3 \mathrm{~cm}^{2} \pm 6.5$ versus $21.5 \mathrm{~cm}^{2} \pm 5.2 ; P<0.05$, resp.). An evaluation of the association between right cardiac function and arterial blood gas was performed using multivariable linear correlation. Significant correlation was observed between low values of $\mathrm{PaO}_{2}$ and larger area of the right atrium $(P<0.05 ; r=-0.72)$ (Figure 1$)$. The study of PAPs showed values significantly higher in severe COPD patients $(45.3 \mathrm{mmHg} \pm 3.5$ versus $30.2 \mathrm{mmHg} \pm 2.3 ; P<0.05)$ and we noted a significant correlation between $\mathrm{PaO}_{2}$ in all patients studied $(P<0.05 ; r=-0.64)$ (Figure 2$)$.

The measurement of TAPSE showed a significant right ventricular dysfunction in all patients but especially in severe COPD patients $(14 \mathrm{~mm} / \mathrm{s} \pm 6$ versus $11.2 \mathrm{~mm} / \mathrm{s} \pm 2.4 ; P<$ $0.05)$ and we correlated the values of TAPSE with arterial blood gas. Thus we have obtained a significant correlation between TAPSE with $\mathrm{PaO}_{2}(P<0.05 ; r=0.56)$ (Figure 3$)$ and TAPSE with $\mathrm{PaCO}_{2}(P<0.05 ; r=-0.55)$ (Figure 4$)$.

All patients were subjected to the Saint George's Respiratory Questionnaire but we did not find any significant association with parameters evaluated. 
TABLE 2: Patients main clinical and instrumental parameters (data expressed as mean \pm standard deviation).

\begin{tabular}{lccc}
\hline Variables & Moderate COPD $(n=21)$ & Severe COPD $(n=35)$ & $P$ value \\
\hline $\mathrm{FEV}_{1} \%$ & $66 \pm 4.3$ & $44.1 \pm 5.2$ & $0.062^{\mathrm{a}}$ \\
$\mathrm{pH}$ & $7.38 \pm 0.02$ & $7.32 \pm 0.03$ & $0.2^{\mathrm{a}}$ \\
$\mathrm{PaO}_{2} \mathrm{mmHg}$ & $64.2 \pm 4.6$ & $56.5 \pm 2.96$ & $0.05^{\mathrm{a}}$ \\
$\mathrm{PaCO}_{2} \mathrm{mmHg}$ & $55.2 \pm 3.5$ & $72.6 \pm 5.3$ & $0.05^{\mathrm{a}}$ \\
$\mathrm{HCO}^{3-} \mathrm{mmol} / \mathrm{L}$ & $30.2 \pm 3.2$ & $37.9 \pm 5.3$ & $0.256^{\mathrm{a}}$ \\
$\mathrm{SO}_{2} \%$ & $92.5 \pm 2.2$ & $89.2 \pm 2.7$ & $0.33^{\mathrm{a}}$ \\
$\mathrm{EF} \%$ & $51.2 \pm 2.7$ & $36.3 \pm 6.3$ & $0.652^{\mathrm{a}}$ \\
$\mathrm{TDLVD}$ mm & $46.7 \pm 4$ & $52.3 \pm 3$ & $0.07^{\mathrm{a}}$ \\
$\mathrm{PP}$ mm & $9 \pm 1$ & $8.2 \pm 3$ & $0.72^{\mathrm{a}}$ \\
SIV mm & $10.4 \pm 2$ & $9.6 \pm 3$ & $0.725^{\mathrm{a}}$ \\
Left atrial area $\left(\mathrm{cm}^{2}\right)$ & $21.7 \pm 4$ & $27.3 \pm 5$ & $0.062^{\mathrm{a}}$ \\
RVSP mmHg & $38.2 \pm 2.9$ & $42.4 \pm 4.7$ & $0.06^{\mathrm{a}}$ \\
PASP mmHg & $30.2 \pm 2.3$ & $45.3 \pm 3.5$ & $0.05^{\mathrm{a}}$ \\
TAPSE mm/s & $14 \pm 6$ & $11.2 \pm 2.4$ & $0.05^{\mathrm{a}}$ \\
Right atrial area $\left(\mathrm{cm}^{2}\right)$ & $21.5 \pm 5.2$ & $33.3 \pm 6.5$ & $0.05^{\mathrm{a}}$ \\
PVR wood units & $1.6 \pm 0.4$ & $4.9 \pm 1.6$ & $0.07^{\mathrm{a}}$ \\
SGRQ & $36 \pm 14$ & $41 \pm 16$ & $0.06^{\mathrm{a}}$ \\
\hline
\end{tabular}

${ }^{a}$ Student $t$-test for unpaired data;

$\mathrm{FEV}_{1}$ : forced expiratory volume in one second; $\mathrm{PaO}_{2}$ : partial pressure of oxygen; $\mathrm{PaCO}_{2}$ : carbon dioxide partial pressure; $\mathrm{HCO}^{3-}$ : bicarbonate ion; $\mathrm{SO}_{2}$ : oxygen saturation; EF: ejection fraction; TDLVD: telediastolic left ventricular diameter; PP: left ventricular posterior wall thickness; SIV: interventricular septum thickness; RVSP: right ventricular systolic pressure; PASP: pulmonary artery systolic pressure; TAPSE: tricuspid annular plane systolic excursion; PVR: pulmonary vascular resistance; COPD: chronic obstructive pulmonary disease; SGRQ: the Saint George's Respiratory Questionnaire.

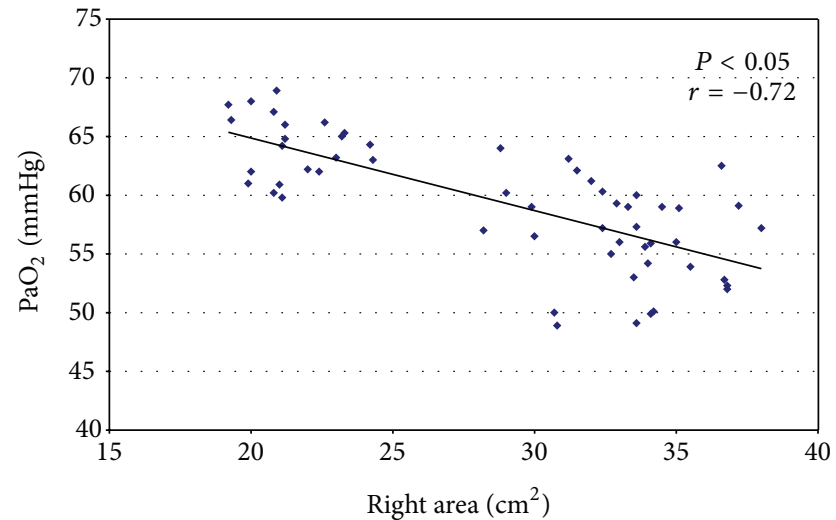

Figure 1: Correlation between low values of $\mathrm{PaO}_{2}$ and larger area of the right atrium.

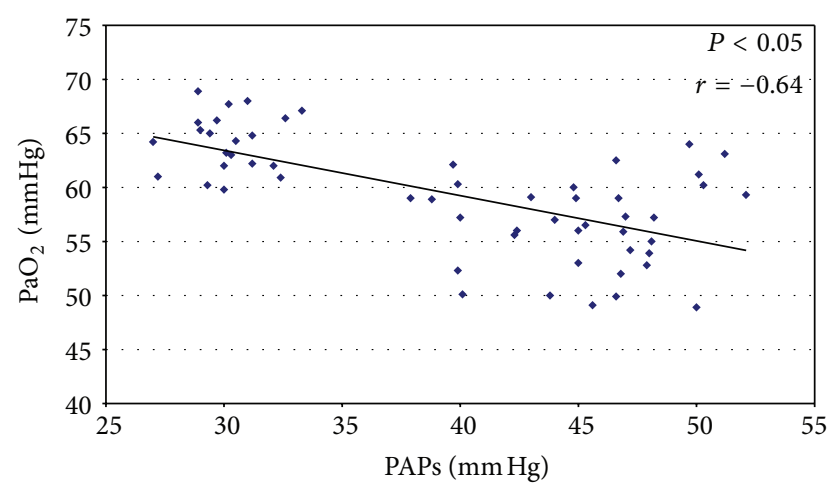

Figure 2: Inverse correlation between $\mathrm{PaO}_{2}$ and PAPs.

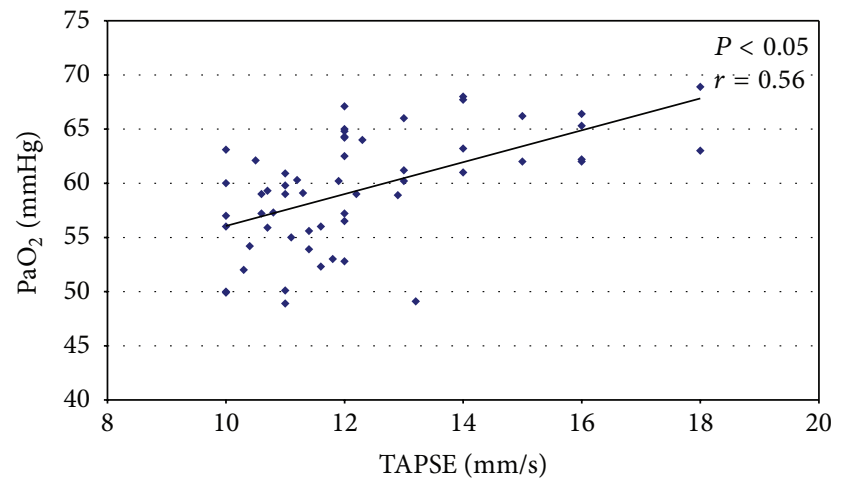

FIgURE 3: Direct correlation between TAPSE and $\mathrm{PaO}_{2}$.

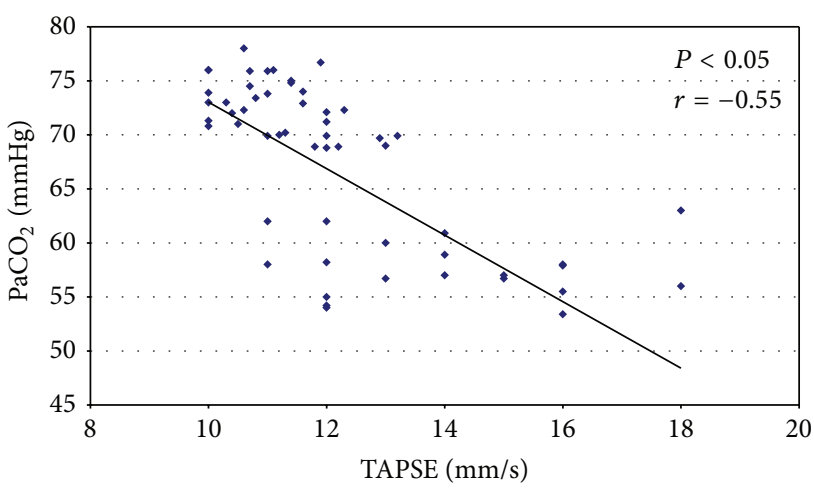

FIgURE 4: Inverse correlation between TAPSE and $\mathrm{PaCO}_{2}$. 


\section{Discussion}

Nowadays the link between chronic respiratory failure in COPD patients and pulmonary hypertension is already widely known. Lung injury induces a progressive reduction in alveolar ventilation. This causes hypoxia which leads to a hypoxic vasoconstriction which increases pulmonary vascular resistance causing hypertension $[14,16,37]$.

A study published by Cuttica et al. [38] evaluated 74 patients with COPD. They have examined a possible correlation between the metres walked in the six-minute walking test $(6 \mathrm{MWT})$ and $\mathrm{FEV}_{1}$, but a significant correlation was not found. This study evaluated a possible correlation between the degree of dyspnea examined by BODE or mMRC and $\mathrm{FEV}_{1}$, showing only a link between $\mathrm{FEV}_{1}$ and BODE. Similarly in our study we evaluated the degree of dyspnea in patients with moderate or severe COPD with SGRQ but we did not find any correlation statistically significant between the obstruction and the worsening in symptoms at rest. Moreover Cuttica examined the link between PAPs and right atrium area showing a correlation between pulmonary hypertension and anatomical changes of the right heart. In our study we evaluated a correlation between PAPs and arterial blood gas showing how hypoxia in COPD patients causes pulmonary hypertension. Moreover we also stressed a correlation between the atrium area and $\mathrm{PaO}_{2}$ showing how the hypoxemia may be considered a negative prognostic factor for right heart failure.

TAPSE is a useful surrogate for right ventricular ejection fraction (EFRV), which indicates the degree of the right ventricular function. The TAPSE estimates the RV systolic function by measuring the level of systolic excursion of the lateral tricuspid valve annulus towards the apex. In a review Bleeker et al. [23] report several studies [27-29] showing an excellent correlation between the TAPSE and RV ejection fraction as assessed by radionuclide angiography. This approach appears to be reproducible and a strong predictor of prognosis in heart failure [23]. In our study we associated TAPSE with $\mathrm{PaO}_{2}$ and $\mathrm{PaCO}_{2}$ in COPD patients and we have shown that hypoxemia is positively correlated with lower values of TAPSE. At opposite hypercapnia is inversely correlated with TAPSE. This relation was independent of the severity of COPD as measured by $\mathrm{FEV}_{1}$ as well as the degree of dyspnea. These correlations further demonstrate the relationship between respiratory failure and right heart failure.

Ghio et al. [27] in a study on the right ventricular systolic function and pulmonary artery pressure sought a better understanding of the coupling between EFRV and PAPs, as it could improve the accuracy of prognostic stratification of patients with heart failure. In fact RV dysfunction is caused by an increase in afterload. Overloading of the pulmonary circle not only causes alterations of the right heart function but also worsens gas exchanges. In fact, we have been able to demonstrate the relationship between ventricular function, expressed indirectly by TAPSE, and hypoxemia.

In conclusion, in patients with chronic respiratory failure, blood gas parameters should not only be considered as parameters to assess the degree of respiratory failure but also as negative prognostic factors of right heart failure. Respiratory failure, in fact, shows a relationship with pulmonary hypertension and with the anatomy and function of the right sections of the heart.

\section{Conflict of Interests}

The authors declare no conflict of interests regarding the publication of this paper.

\section{References}

[1] Global Iniziative for Chronic Obstructive Lung Disease, GOLD Guidelines, 2013.

[2] C. Terzano, S. Romani, G. Paone, V. Conti, and F. Oriolo, "COPD and thyroid dysfunctions," Lung, vol. 192, no. 1, pp. 103109, 2014.

[3] C. D. Mathers and D. Loncar, "Projections of global mortality and burden of disease from 2002 to 2030," PLoS Medicine, vol. 3, no. 11, article e442, pp. 2011-2030, 2006.

[4] J. C. Bestall, E. A. Paul, R. Garrod, R. Garnham, P. W. Jones, and J. A. Wedzicha, "Usefulness of the Medical Research Council (MRC) dyspnoea scale as a measure of disability in patients with chronic obstructive pulmonary disease," Thorax, vol. 54, no. 7, pp. 581-586, 1999.

[5] P. W. Jones, F. H. Quirk, C. M. Baveystock, and P. Littlejohns, "A self-complete measure of health status for chronic airflow limitation. The St. George's Respiratory Questionnaire.," American Review of Respiratory Disease, vol. 145, no. 6, pp. 1321-1327, 1992.

[6] C. R. Jenkins, P. W. Jones, P. M. Calverley et al., "Efficacy of salmeterol/fluticasone propionate by GOLD stage of chronic obstructive pulmonary disease: analysis from the randomised, placebo-controlled TORCH study," Respiratory Research, vol. 10, article 59, 2009.

[7] F. Holguin, E. Folch, S. C. Redd, and D. M. Mannino, "Comorbidity and mortality in COPD-related hospitalizations in the United States, 1979 to 2001," Chest, vol. 128, no. 4, pp. 2005-2011, 2005.

[8] M. van den Akker, F. Buntinx, J. F. M. Metsemakers, S. Roos, and J. A. Knottnerus, "Multimorbidity in general practice: prevalence, incidence and determinants of co-occurring chronic and recurrent diseases," Journal of Clinical Epidemiology, vol. 51, no. 5, pp. 367-375, 1998.

[9] S. Sidney, M. Sorel, C. P. Quesenberry Jr., C. DeLuise, S. Lanes, and M. D. Eisner, "COPD and incident cardiovascular disease hospitalizations and mortality: Kaiser Permanente Medical Care Program," Chest, vol. 128, no. 4, pp. 2068-2075, 2005.

[10] H. Ni, D. Nauman, and R. E. Hershberger, "Managed care and outcomes of hospitalization among elderly patients with congestive heart failure," Archives of Internal Medicine, vol. 158, no. 11, pp. 1231-1236, 1998.

[11] M. Lainscak, L. M. Hodoscek, H. D. Düngen et al., "The burden of chronic obstructive pulmonary disease in patients hospitalized with heart failure," Wiener Klinische Wochenschrift, vol. 121, no. 9-10, pp. 309-313, 2009.

[12] C. Ukena, F. Mahfoud, M. Kindermann et al., "The cardiopulmonary continuum systemic inflammation as "common soil" of heart and lung disease," International Journal of Cardiology, vol. 145, no. 2, pp. 172-176, 2010.

[13] S. M. Curkendall, C. DeLuise, J. K. Jones et al., "Cardiovascular disease in patients with chronic obstructive pulmonary 
disease, Saskatchewan Canada: cardiovascular disease in COPD patients," Annals of Epidemiology, vol. 16, no. 1, pp. 63-70, 2006.

[14] N. Galiè, M. M. Hoeper, M. Humbert et al., "Guidelines for the diagnosis and treatment of pulmonary hypertension," European Heart Journal, vol. 30, no. 20, pp. 2493-2537, 2009.

[15] S. Eddahibi, A. Chaouat, N. Morrell et al., "Polymorphism of the serotonin transporter gene and pulmonary hypertension in chronic obstructive pulmonary disease," Circulation, vol. 108, no. 15, pp. 1839-1844, 2003.

[16] E. Weitzenblum, A. Sautegeau, M. Ehrhart, M. Mammosser, and A. Pelletier, "Long-term oxygen therapy can reverse the progression of pulmonary hypertension in patients with chronic obstructive pulmonary disease," American Review of Respiratory Disease, vol. 131, no. 4, pp. 493-498, 1985.

[17] M. Oswald-Mammosser, E. Weitzenblum, E. Quoix et al., "Prognostic factors in COPD patients receiving long-term oxygen therapy: importance of pulmonary artery pressure," Chest, vol. 107, no. 5, pp. 1193-1198, 1995.

[18] A. C. Stone, J. T. Machan, J. Mazer, B. Casserly, and J. R. Klinger, "Echocardiographic evidence of pulmonary hypertension is associated with increased 1-year mortality in patients admitted with chronic obstructive pulmonary disease," Lung, vol. 189, no. 3, pp. 207-212, 2011.

[19] J. P. Wrobel, C. A. McLean, B. R. Thompson et al., "Pulmonary arterial remodeling in chronic obstructive pulmonary disease is lobe dependent," Pulmonary Circulation, vol. 3, no. 3, pp. 665674, 2013.

[20] D. M. Toraldo, M. Minelli, F. de Nuccio, and G. Nicolardi, "Chronic obstructive pulmonary disease phenotype desaturator with hypoxic vascular remodelling and pulmonary hypertension obtained by cluster analysis," Multidisciplinary Respiratory Medicine, vol. 7, no. 1, article 39, 2012.

[21] K. H. Andersen, M. Iversen, J. Kjaergaard et al., "Prevalence, predictors, and survival in pulmonary hypertension related to end-stage chronic obstructive pulmonary disease," Journal of Heart and Lung Transplantation, vol. 31, no. 4, pp. 373-380, 2012.

[22] S. Y. Ho and P. Nihoyannopoulos, "Anatomy, echocardiography, and normal right ventricular dimensions," Heart, vol. 92, supplement 1, pp. i2-i13, 2006.

[23] G. B. Bleeker, P. Steendijk, E. R. Holman et al., "Assessing right ventricular function: the role of echocardiography and complementary technologies," Heart, vol. 92, supplement 1, pp. i19-i26, 2006.

[24] W. Burger, B. Jockwig, G. Rücker, and G. Kober, "Influence of right ventricular pre- and afterload on right ventricular ejection fraction and preload recruitable stroke work relation," Clinical Physiology, vol. 21, no. 1, pp. 85-92, 2001.

[25] F. Haddad, R. Doyle, D. J. Murphy, and S. A. Hunt, "Right ventricular function in cardiovascular disease, part II: pathophysiology, clinical importance, and management of right ventricular failure," Circulation, vol. 117, no. 13, pp. 1717-1731, 2008.

[26] A. Vitarelli and C. Terzano, "Do we have two hearts? New insights in right ventricular function supported by myocardial imaging echocardiography," Heart Failure Reviews, vol. 15, no. 1, pp. 39-61, 2010.

[27] S. Ghio, F. Recusani, C. Klersy et al., "Prognostic usefulness of the tricuspid annular plane systolicexcursion in patients with congestive heart failure secondary to idiopathic or ischemic dilated cardiomyopathy," American Journal of Cardiology, vol. 85, no. 7, pp. 837-842, 2000.
[28] S. Kaul, C. Tei, J. M. Hopkins, and P. M. Shah, "Assessment of right ventricular functionusing two-dimensional echocardiography," American Heart Journal, vol. 107, no. 3, pp. 526-531, 1984.

[29] J. L. Smith, E. L. Bolson, S. P. Wong, M. Hubka, and F. H. Sheehan, "Three-dimensional assessment of two-dimensionaltechnique for evaluation of right ventricular function by tricuspid annulus motion," International Journal of Cardiovascular Imaging, vol. 19, no. 3, pp. 189-197, 2003.

[30] A. López-Candales, N. Rajagopalan, N. Saxena, B. Gulyasy, K. Edelman, and R. Bazaz, "Right ventricular systolic function is not the sole determinant of tricuspid annular motion," American Journal of Cardiology, vol. 98, no. 7, pp. 973-977, 2006.

[31] P. R. Forfia, M. R. Fisher, S. C. Mathai et al., "Tricuspid annular displacement predicts survival in pulmonary hypertension," American Journal of Respiratory and Critical Care Medicine, vol. 174, no. 9, pp. 1034-1041, 2006.

[32] A. J. France, R. J. Prescott, W. Biernacki, A. L. Muir, and W. MacNee, "Does right ventricular function predict survival in patients with chronic obstructive lung disease?" Thorax, vol. 43, no. 8, pp. 621-626, 1988.

[33] M. Burgess, N. Mogulkoc, R. Bright-Thomas, P. Bishop, J. J. Egan, and S. G. Ray, "Comparison of echocardiographic markers of right ventricular function in determining prognosis in chronic pulmonary disease," Journal of the American Society of Echocardiography, vol. 15, no. 6, pp. 633-639, 2002.

[34] R. M. Lang, M. Bierig, R. B. Devereux et al., "Recommendations for chamber quantification: a report from the American Society of Echocardiography's guidelines and standards committee and the Chamber Quantification Writing Group, developed in conjunction with the European Association of Echocardiography, a branch of the European Society of Cardiology," Journal of the American Society of Echocardiography, vol. 18, no. 12, pp. 14401463, 2005.

[35] L. G. Rudski, W. W. Lai, J. Afilalo et al., "Guidelines for the Echocardiographic Assessment of the Right Heart in Adults: a report from the American Society of Echocardiography endorsed by the European Association of Echocardiography, a registered branch of the European Society of Cardiology, and the Canadian Society of Echocardiography," Journal of the American Society of Echocardiography, vol. 23, no. 7, pp. 685-713, 2010.

[36] M. I. Burgess, R. J. Bright-Thomas, and S. G. Ray, "Echocardiographic evaluation of right ventricular function," European Journal of Echocardiography, vol. 3, no. 4, pp. 252-262, 2002.

[37] S. Eddahibi, A. Chaouat, N. Morrell et al., "Polymorphism of the serotonin transporter gene and pulmonaryhypertension in chronic obstructive pulmonary disease," Circulation, vol. 108, no. 15, pp. 1839-1844, 2003.

[38] M. J. Cuttica, S. J. Shah, S. R. Rosenberg et al., "Right heart structural changes are independently associated with exercise capacity in non-severe COPD," PLoS ONE, vol. 6, no. 12, Article ID e29069, 2011. 


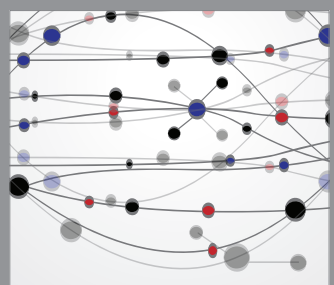

The Scientific World Journal
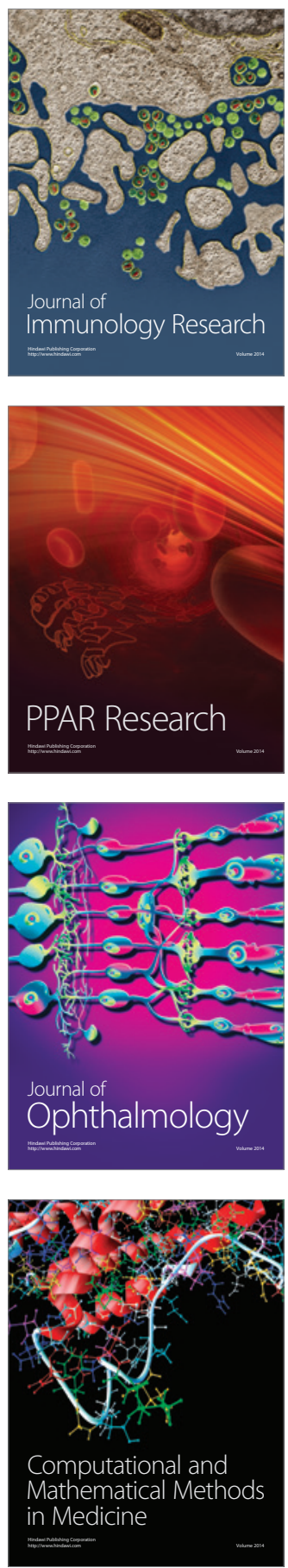

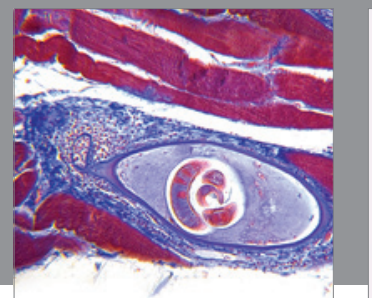

Gastroenterology

Research and Practice
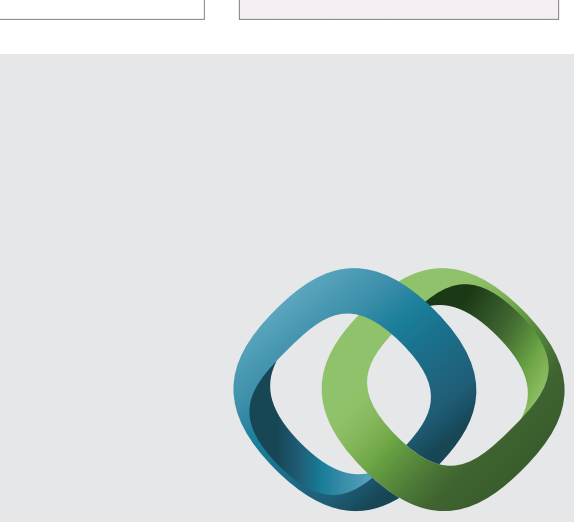

\section{Hindawi}

Submit your manuscripts at

http://www.hindawi.com
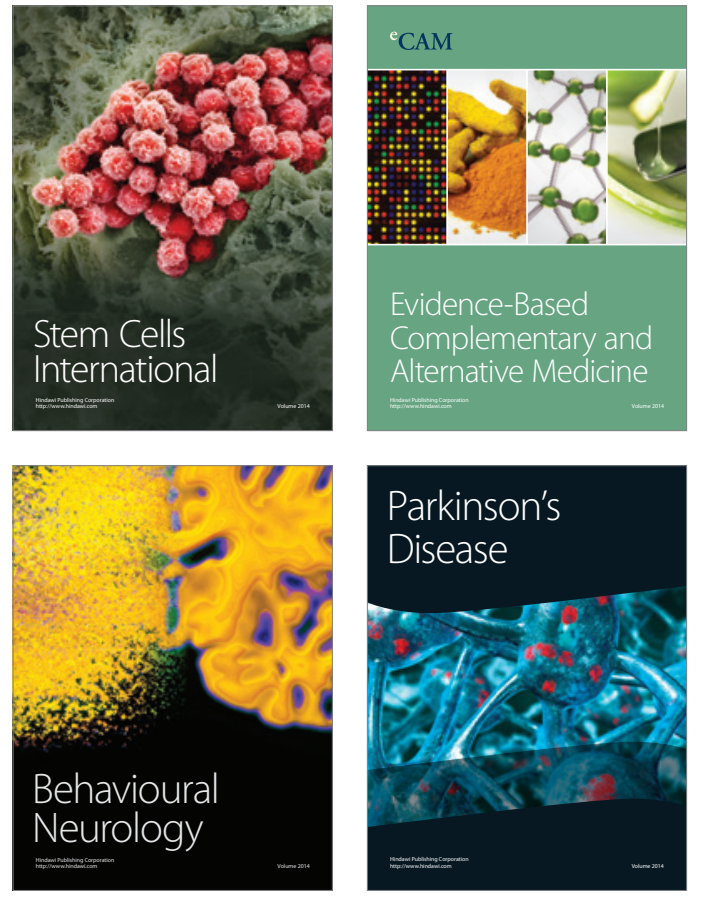
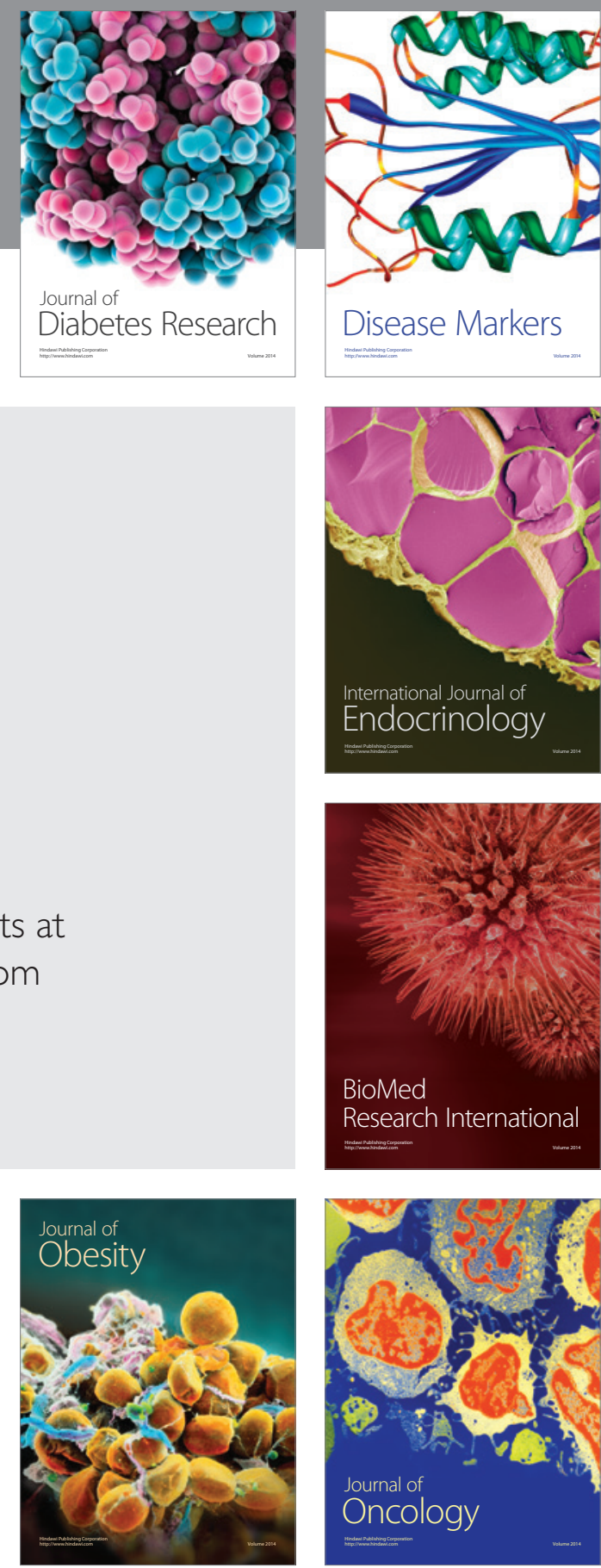

Disease Markers
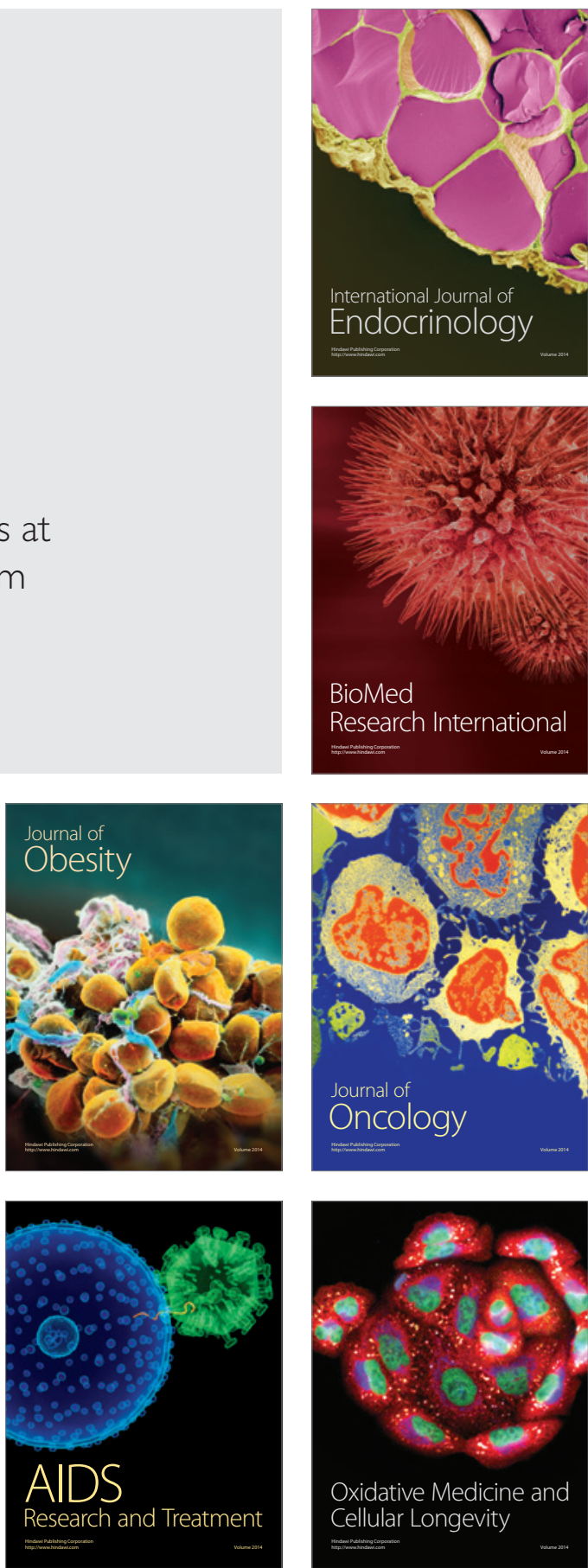